\title{
Genomic and secretomic insight into lignocellulolytic system of an endophytic bacterium Pantoea ananatis Sd-1
}

Jiangshan $\mathrm{Ma}^{1+}{ }^{1}$, Keke Zhang ${ }^{1 \dagger}$, Hongdong Liao ${ }^{1 \dagger}$, Stanton B. Hector ${ }^{2,4}$, Xiaowei Shi $^{1}$, Jianglin Li ${ }^{3}$, Bin Liu ${ }^{1}$, Ting Xu' ${ }^{1}$, Chunyi Tong ${ }^{1}$, Xuanming Liu $^{1^{*}}$ and Yonghua Zhu ${ }^{*^{*}}$ (D)

\begin{abstract}
Background: Exploring microorganisms especially bacteria associated with the degradation of lignocellulosic biomass shows great potentials in biofuels production. The rice endophytic bacterium Pantoea ananatis Sd-1 with strong lignocellulose degradation capacity has been reported in our previous study. However, a comprehensive analysis of its corresponding degradative system has not yet been conducted. The aim of this work is to identify and characterize the lignocellulolytic enzymes of the bacterium to understand its mechanism of lignocellulose degradation and facilitate its application in sustainable energy production.
\end{abstract}

Results: The genomic analysis revealed that there are 154 genes encoding putative carbohydrate-active enzymes (CAZy) in P. ananatis Sd-1. This number is higher than that of compared cellulolytic and ligninolytic bacteria as well as other eight $P$. ananatis strains. The CAZy in $P$. ananatis $S d-1$ contains a complete repertoire of enzymes required for cellulose and hemicellulose degradation. In addition, P. ananatis Sd-1 also possesses plenty of genes encoding potential ligninolytic relevant enzymes, such as multicopper oxidase, catalase/hydroperoxidase, glutathione S-transferase, and quinone oxidoreductase. Quantitative real-time PCR analysis of parts of genes encoding lignocellulolytic enzymes revealed that they were significantly up-regulated (at least $P<0.05$ ) in presence of rice straw. Further identification of secretome of $P$. ananatis Sd-1 by nano liquid chromatography-tandem mass spectrometry confirmed that considerable amounts of proteins involved in lignocellulose degradation were only detected in rice straw cultures. Rice straw saccharification levels by the secretome of $P$. ananatis Sd-1 reached $129.11 \pm 2.7 \mathrm{mg} / \mathrm{gds}$. Correspondingly, the assay of several lignocellulolytic enzymes including endoglucanase, exoglucanase, $\beta$-glucosidase, xylanase-like, lignin peroxidase-like, and laccase-like activities showed that these enzymes were more active in rice straw relative to glucose substrates. The high enzymes activities were not attributed to bacterial cell densities but to the difference of secreted protein contents.

Conclusion: Our results indicate that $P$. ananatis $\mathrm{Sd}-1$ can produce considerable lignocellulolytic enzymes including cellulases, hemicellulases, and ligninolytic relevant enzymes. The high activities of those enzymes could be efficiently induced by lignocellulosic biomass. This identified degradative system is valuable for the lignocellulosic bioenergy industry.

Keywords: Endophytic bacterium, Pantoea ananatis Sd-1, Lignocellulose degradation, CAZy, Quantitative real-time $P C R$, Secretome, Enzymes activities

\footnotetext{
*Correspondence: xml05@hnu.edu.cn; yonghuaz@outlook.com

${ }^{\dagger}$ Jiangshan Ma, Keke Zhang and Hongdong Liao contributed equally to this work

${ }^{1}$ Hunan Province Key Laboratory of Plant Functional Genomics

and Developmental Regulation, College of Biology, Hunan University,

Changsha 410008, Hunan, People's Republic of China

Full list of author information is available at the end of the article
} 


\section{Background}

Lignocellulose in vascular plant cell walls is the largest reservoir of organic polymers in terrestrial ecosystems and is a potential biofuel feedstock alternative to petroleum [1]. The main components of lignocellulose are polysaccharides and lignin. They are bound together in a matrix and the recalcitrance of structure gives rise to a major bottleneck in the efficient conversion of lignocellulosic biomass to biofuels [2]. Thus, exploring highly efficient lignocellulose decomposition microorganisms has attracted significant research attention [3]. During the past decade, only a limited number of microorganisms, such as various types of fungi, were found to breakdown the complex lignocellulose polymer structures [4]. Recently, bacterial systems have attracted an increasing amount of attention due to their unique mechanisms for lignocellulose decomposition and the high specificity of their lignocellulolases. Bacteria also have great advantages over fungi due to their rapid growth, wide range of environmental adaptability, and facilitative genetic manipulations $[5,6]$.

Bacterial candidates for degrading lignocellulosic polysaccharides have been identified by genomic and proteomic analysis. Caldicellulosiruptor bescii DSM 6725, Clostridium thermocellum ATCC 27405 and Streptomyces SDPB6 had been sequenced, and a lot of genes in these bacteria strains encoding putative carbohydrate-active enzymes (CAZy) were identified, and their presence were partially confirmed by proteomic analysis results [7-9]. Recently, qualitative and quantitative proteomic analysis methods were used to demonstrate that lignocellulolytic enzymes in Thermobifida fusca were highly up-regulated in the presence lignocellulosic biomass [10-12]. However, bacterium that can degrade both lignocellulosic polysaccharides and lignin was rarely found [13, 14], let alone a comprehensive research of the lignocellulolytic system, including cellulases, hemicellulases, and ligninolytic enzymes in the bacteria was reported.

Endophytes which spend the whole or part of its life cycle colonizing inside the healthy host plant tissues have been the subject of research attention worldwide, due to its wide distribution and the ability to produce a wide variety of secondary metabolites. They can secrete a large number of proteins, including lignocellulolytic enzymes, to assist their adaption and survival within higher plants [15]. A few endophytic fungi demonstrating lignocellulosic biomass degrading ability have already been discovered $[16,17]$. However, endophytic bacteria as potential lignocellulose degradation resources have been largely overlooked.

We have isolated a rice endophytic bacterium Pantoea sp. Sd-1 (China General Microbiological Culture Collection Centre, no. 6698). It showed strong lignocellulosic biomass degradation capacity with $54.5 \%$ of rice straw weight lost (cellulose, hemicellulose, and lignin content reduced 80.1, 59.6, and $33.1 \%$, respectively) after 6 days treatment and kraft lignin content reduced $69.1 \%$ after 4 days incubation [18]. It was further identified as Pantoea ananatis $\mathrm{Sd}-1$ by whole genome sequencing analysis. Generally the Pantoea genus is recognized for its plant pathogenesis [19]. However, it has also been reported as lignocellulose degradation bacterium. Pantoea sp. SL1_M5 isolated from invasive woodwasp Sirex noctilio and displayed degrading ability toward cellulose and its derivatives [20]. A few other $P$. ananatis strains were also reported to possess carbohydrate degradation enzymes [14, 21]. Pantoea sp. RCT2 isolated from pulp paper mill effluent and showed ligninolytic enzyme activity and strong pulp paper mill effluent decolorisation capacity [22]. The Pantoea sp NII-153 isolated from soil showed high strength lignin derivative degradation ability [23]. These indicated that Pantoea genus strains might be potential resources for lignocellulosic biomass biotransformation industry.

Pantoea ananatis Sd-1 possesses the degradation ability for both lignocellulosic polysaccharides and lignin. Uncovering corresponding genes and enzymes in its lignocellulolytic system will be essential for its efficient application in biofuel industry. In the present study, we sequenced the whole genome of $P$. ananatis $\mathrm{Sd}-1$ and compared its characteristics to those of five typical cellulolytic and ligninolytic bacteria as well as eight other $P$. ananatis strains. We identified candidate genes involved in lignocellulose degradation through genomic analysis, and some of them were confirmed by analyzing their expression levels. Comparative proteome analysis was also conducted to differentiate the enzyme cocktails produced by $P$. ananatis Sd-1 when it grew on different carbon sources. In addition, this secretome was also evaluated for rice straw saccharification. Furthermore, several typical lignocellulolytic enzymes activity were detected and compared.

\section{Results}

\section{Genomic analysis of $P$. ananatis Sd-1}

The assembled genome of $P$. ananatis Sd-1 [GenBank: AZTE00000000] comprises a total of 4927,500 bp containing 4332 protein coding sequences (CDS) (detailed results were shown in Additional file 1: Table S1). To identify genes involved in lignocellulose degradation, CDS were analyzed using dbCAN carbohydrate-active enzymes (CAZy) annotation algorithm. Results indicated that 154 genes have multiple domains assigned to CAZy families, including 59 glycoside hydrolases (GHs), 25 carbohydrate esterases (CEs), 2 polysaccharide lyases (PLs), 9 enzymes with auxillary activities (AAs), and 11 carbohydrate binding modules (CBMs); 28 of these proteins 
contain signal peptides and are predicted to be extracellular proteins (Additional file 2: Table S2).

The genome characteristics of $P$. ananatis $\mathrm{Sd}-1$ was compared with five well-studied cellulolytic and ligninolytic bacteria: Pantoea sp. SL1_M5 [GenBank: ADWZ00000000] [20], C. bescii DSM 6725 [GenBank: CP001393] [7], C. thermocellum ATCC 27405 [GenBank: CP000568] [8], Sphingobium sp. SYK-6 [GenBank: AP012222] [24], and Enterobacter lignolyticus SCF1 [GenBank: CP002272] [25], and eight reported P. ananatis strains with potential carbohydrate degradation ability [21]: P. ananatis AJ13355 [GenBank: AP012032], P. ananatis LMG 20103 [GenBank: CP001875], P. ananatis LMG 5342 [GenBank: HE617160], P. ananatis PA13 [GenBank: CP003085], P. ananatis B1-9 [GenBank: CAEJ00000000], $P$. ananatis LMG 2665 [GenBank: JMJJ00000000], P. ananatis PA4 [GenBank: JMJK00000000], and P. ananatis BD442 [GenBank: JMJL00000000]. The number of putative CAZy genes in P. ananatis Sd-1 (154) is the highest, and the percentage of putative CAZy genes (3.6\%) is the second highest among all compared strains (Table 1). $P$. ananatis $\mathrm{Sd}-1$, the eight other $P$. ananatis strains and the cellulolytic bacterium $C$. bescii DSM 6725 possess similar numbers of GHs and CBMs, which are only less than those of the cellulolytic bacterium C. thermocellum ATCC 27405. The amounts of CEs and AAs in P. ananatis Sd-1 are significantly higher than those in all compared strains, including the eight $P$. ananatis strains. It is also worth mentioning that AAs were absent from the five other cellulolytic and ligninolytic bacteria as well as two $P$. ananatis strains. We only found one AA in $P$. ananatis AJ13355, $P$. ananatis LMG 20103, $P$. ananatis B1-9, $P$. ananatis LMG 2665, $P$. ananatis PA4, and $P$. ananatis BD442.

In $P$. ananatis $\mathrm{Sd}-1$, there are 10 cellulase genes including: one endoglucanase (GH8) gene, one exoglucanase (GH10) gene, and eight $\beta$-glucosidase genes (GH1, 3) (Table 2). Among those cellulases, four proteins sequences including endoglucanase and exoglucanase exhibit potential secretion signals. The number of cellulase genes in $P$. ananatis $\mathrm{Sd}-1$ is the same as that found in the eight compared $P$. ananatis strains, which is only less than that possessed by the cellulolytic bacterium $C$. thermocellum ATCC 27405 (16).

Similar to the eight compared $P$. ananatis strains, there are five GHs containing CBM domains in $P$. ananatis Sd-1 (Additional file 3: Figure S1), which are surprisingly not related to cellulose degradation. However, there are three cellulase genes containing multiple CBM domains in cellulolytic bacterium $C$. bescii DSM 6725, and the majority of cellulase system-related genes comprise multiple CBM domains in cellulolytic bacterium $C$. thermocellum ATCC 27405.

Although there are no typical xylanase genes in $P$. ananatis Sd-1, we found nine esterases (CE1, 3, 10, 16)

Table 1 Comparison of genome of $P$. ananatis Sd-1 with cellulolytic, ligninolytic bacteria, and other $P$. ananatis strains

\begin{tabular}{|c|c|c|c|c|c|c|c|c|c|}
\hline Species & Genome size (bp) & Protein coding genes & Total CAZy & $\%$ CAZy $^{a}$ & $\mathrm{GHs}^{\mathrm{c}}$ & $\mathrm{CEs}^{\mathrm{d}}$ & $\mathrm{CBMs}^{\mathrm{e}}$ & $P L s^{f}$ & $A A s^{g}$ \\
\hline P. ananatis Sd-1 & $4,927,500$ & 4332 & 154 & 3.6 & 59 & 25 & 11 & 2 & 9 \\
\hline P. ananatis AJ13355 & $4,877,280$ & 4222 & 108 & 2.6 & 52 & 4 & 9 & 0 & 1 \\
\hline P. ananatis LMG 2013 & $4,703,370$ & 4076 & 105 & 2.6 & 51 & 4 & 8 & 0 & 1 \\
\hline P. ananatis LMG 5342 & $4,908,140$ & 4345 & 108 & 2.5 & 55 & 4 & 10 & 0 & 0 \\
\hline P. ananatis PA13 & $4,867,130$ & 4403 & 112 & 2.5 & 59 & 4 & 10 & 0 & 0 \\
\hline P. ananatis B1-9 & $5,105,560$ & 4672 & 129 & 2.8 & 58 & 9 & 10 & 2 & 1 \\
\hline P. ananatis LMG 2665 & $4,633,915$ & 4397 & 123 & 2.8 & 55 & 9 & 10 & 2 & 1 \\
\hline P. ananatis PA4 & $5,163,480$ & 4662 & 131 & 2.8 & 60 & 7 & 13 & 2 & 1 \\
\hline P. ananatis BD442 & $4,798,550$ & 4292 & 125 & 2.9 & 55 & 8 & 11 & 2 & 1 \\
\hline Pantoea sp. SL1_M5 & $4,924,830$ & 4626 & 41 & 0.9 & 28 & 2 & 3 & 0 & 0 \\
\hline C. thermocellum ATCC 27405 & $3,843,300$ & 3263 & 145 & 4.4 & 74 & 16 & 90 & 4 & 0 \\
\hline C. bescii DSM 6725 & $2,931,660$ & 2662 & 88 & 3.3 & 49 & 6 & 18 & 3 & 0 \\
\hline Sphingobium sp. SYK-6 & $4,348,130$ & 3939 & 70 & 1.7 & 21 & 1 & 3 & 0 & 0 \\
\hline E. lignolyticus SCF1 & $4,814,050$ & 4350 & 94 & 2.1 & 42 & 5 & 7 & 0 & 0 \\
\hline
\end{tabular}

a Percentage of CAZy genes in protein coding genes

b CAZy carbohydrate-active enzymes

c GHs glycoside hydrolases

d CEs carbohydrate esterases

e CBMs carbohydrate bingding modules

f $P L s$ polysaccharide lyases

g AAs auxillary activities 
Table 2 Predicted CAZymes and other potential lignocellulolytic enzymes in the P. ananatis Sd-1 genome

\begin{tabular}{|c|c|c|c|c|}
\hline Enzymes & Specific activity & Locus tag & CAZy modules & Signal peptides \\
\hline \multirow[t]{28}{*}{ Cellulose and hemicellulose degradation relevant enzymes } & Endoglucanases & Y903_RS0123720 & $\mathrm{GH} 8$ & Y \\
\hline & Exoglucanases & Y903_RS0108720 & $\mathrm{GH} 10$ & Y \\
\hline & \multirow[t]{8}{*}{$\beta$-glucosidases } & Y903_RS0109910 & $\mathrm{GH} 1$ & N \\
\hline & & Y903_RS0123340 & $\mathrm{GH} 1$ & Y \\
\hline & & Y903_RS0115000 & $\mathrm{GH} 1$ & $\mathrm{~N}$ \\
\hline & & Y903_RS0103625 & $\mathrm{GH} 1$ & $\mathrm{~N}$ \\
\hline & & Y903_RS0104945 & $\mathrm{GH} 1$ & N \\
\hline & & Y903_RS0106975 & $\mathrm{GH} 1$ & $\mathrm{~N}$ \\
\hline & & Y903_RS0113180 & $\mathrm{GH} 3$ & Y \\
\hline & & Y903_RS0116520 & $\mathrm{GH} 3$ & $\mathrm{~N}$ \\
\hline & \multirow[t]{4}{*}{ Oxidoreductase } & Y903_RS0100765 & GH109 & $\mathrm{N}$ \\
\hline & & Y903_RS0119930 & GH109 & $\mathrm{N}$ \\
\hline & & Y903_RS0103245 & GH109 & N \\
\hline & & Y903_RS0108420 & GH109 & $\mathrm{N}$ \\
\hline & \multirow[t]{2}{*}{ a-N-arabinofuranosidase } & Y903_RS0119145 & $\mathrm{GH} 43$ & $\mathrm{~N}$ \\
\hline & & Y903_RS0120675 & GH51 & $\mathrm{N}$ \\
\hline & a-mannosidase & Y903_RS0105780 & $\mathrm{GH} 38$ & $\mathrm{~N}$ \\
\hline & \multirow[t]{2}{*}{ Galactosidase } & Y903_RS0108500 & $\mathrm{GH} 2$ & $\mathrm{~N}$ \\
\hline & & Y903_RS0110160 & $\mathrm{GH} 4$ & $\mathrm{~N}$ \\
\hline & \multirow[t]{5}{*}{ Esterase } & Y903_RS0100380 & CE1 & $\mathrm{N}$ \\
\hline & & Y903_RS0104455 & CE10 & Y \\
\hline & & Y903_RS0104990 & CE16 & N \\
\hline & & Y903_RS0120815 & CE10 & Y \\
\hline & & Y903_RS0117780 & CE10 & Y \\
\hline & Acyl-CoA esterase & Y903_RS0113655 & CE1 & N \\
\hline & Acyl-CoA thioesterase & Y903_RS0114420 & CE3 & N \\
\hline & \multirow[t]{2}{*}{ Carboxylesterase } & Y903_RS0117855 & CE1 & N \\
\hline & & Y903_RS0116340 & CE10 & N \\
\hline \multirow[t]{18}{*}{ Lignin degradation relevant enzymes } & \multirow[t]{2}{*}{ Multicopper oxidase } & Y903_RS0111680 & - & Y \\
\hline & & Y903_RS0119240 & - & Y \\
\hline & Catalase/hydroperoxidase & Y903_RS0115335 & AA2 & $\mathrm{N}$ \\
\hline & GMC family oxidoreductase & Y903_RS0107765 & AA3 & N \\
\hline & \multirow[t]{10}{*}{ Quinone oxidoreductase } & Y903_RS0112360 & - & N \\
\hline & & Y903_RS0117910 & - & N \\
\hline & & Y903_RS0118595 & - & $\mathrm{N}$ \\
\hline & & Y903_RS0110255 & - & N \\
\hline & & Y903_RS0120835 & - & N \\
\hline & & Y903_RS0120850 & - & N \\
\hline & & Y903_RS0120855 & - & N \\
\hline & & Y903_RS0120880 & - & $\mathrm{N}$ \\
\hline & & Y903_RS0105425 & - & $\mathrm{N}$ \\
\hline & & Y903_RS0107980 & - & $\mathrm{N}$ \\
\hline & \multirow[t]{4}{*}{ Glutathione S-transferase } & Y903_RS0123560 & - & $\mathrm{N}$ \\
\hline & & Y903_RS0108490 & - & $\mathrm{N}$ \\
\hline & & Y903_RS0107875 & - & $\mathrm{N}$ \\
\hline & & Y903_RS0120970 & - & $\mathrm{N}$ \\
\hline
\end{tabular}


genes in it (Table 2). Among these esterases, Y903 RS0120815, Y903_RS0117780, and Y903_RS0104455 which all belong to the CE10 family possess signal peptide sequences. In addition, the number of esterases genes in $P$. ananatis $\mathrm{Sd}-1$ is higher than that of all of the compared strains. Furthermore, some GHs involved in hemicellulosic polysaccharides hydrolysis, such as $\alpha-\mathrm{N}$ arabinofuranosidase (GH43, 51), $\alpha$-mannosidase (GH38), and galactosidase $(\mathrm{GH} 2,4)$ have also been found in $P$. ananatis Sd-1 (Table 2).

Several genes encoding proteins potentially involved in lignin degradation were identified in $P$. ananatis Sd-1 (Table 2). These include multicopper oxidases, catalase/ hydroperoxidase (AA2), glucose-methanol-choline (GMC) family oxidoreductase (AA3), glutathione S-transferases (GSTs), and quinone oxidoreductases. Phylogenetic analysis revealed that the GMC family oxidoreductase was closely related to pyranose oxidases (Fig. 1a). There are seven GST in $P$. ananatis Sd-1. Phylogenetic analysis indicated that gst 1 (Y903_RS0123560), gst3 (Y903_RS0107875), and GST4 (Y903_RS0120970) were closely related to LigG, and GTS2 (Y903_RS0108490) belongs to the LigF group (Fig. 1b). Our analyses indicate that these four GSTs might possess $\beta$-etherase activity. Among the above-mentioned enzymes potentially involved in lignin degradation, only the multicopper oxidases are predicted to be extracellular proteins.

\section{Gene expression analysis for $P$. ananatis Sd-1 cultured in rice straw or glucose medium}

Expression profiles of selected $P$. ananatis Sd-1 lignocellulolytic enzymes genes were monitored in cultures grown on rice straw compared to cultures utilizing glucose as sole carbon source. Quantitative real-time PCR (qRT-PCR) investigation results of genes encoding endoglucanase (egl Y903_RS0123720), exoglucanase (exgl Y903_RS0108720), $\beta$-glucosidase (bgl1 Y903_RS0116520 and bgl2 Y903_RS0113180), esterase (est1 Y903_ RS0120815, est2 Y903_RS0117780, est3 Y903_RS0100380 and est4 Y903_RS0113655), multicopper oxidase (lac3 Y903_RS0111680 and lac4 Y903_RS0119240), catalase/ hydroperoxidase (cat Y903_RS0115335), GMC family oxidoreductase ( $g m c$ Y903_RS0107765), GST (gst1 Y903_RS0123560, gst2 Y903_RS0108490, gst3 Y903_ RS0107875, and gst4 Y903_RS0120970), and quinone oxidoreductase ( $q r d 1$ Y903_RS0107980, qrd2 Y903_ RS0118595, qrd3 Y903_RS0110255, and qrd4 Y903 RS0112360) are shown in Fig. 2. Transcript levels of all the genes of interest were significantly up-regulated (at least $P<0.05)$ in rice straw cultures compared to basic glucose cultures. Remarkably, transcript levels of several cellulase genes (egl, $b g l 1$, and $b g l 2)$, hemicellulase genes (est 1 , est 2 , and est 4 ), and ligninolytic-related genes (lac3, lac4, gmc, gst4, qrd1, qrd2, and qrd3) were increased more than tenfold in rice straw cultures.

\section{Identification of secretomes of $P$. ananatis Sd-1 grown on medium containing with or without rice straw} One-dimensional polyacrylamide gel electrophoresis (1D-PAGE) followed by nano liquid chromatography-tandem mass spectrometry (nanoLC-MS/MS) analysis was used to further identify the lignocellulolytic enzymes system in $P$. ananatis $\mathrm{Sd}-1$ cultured in rice straw
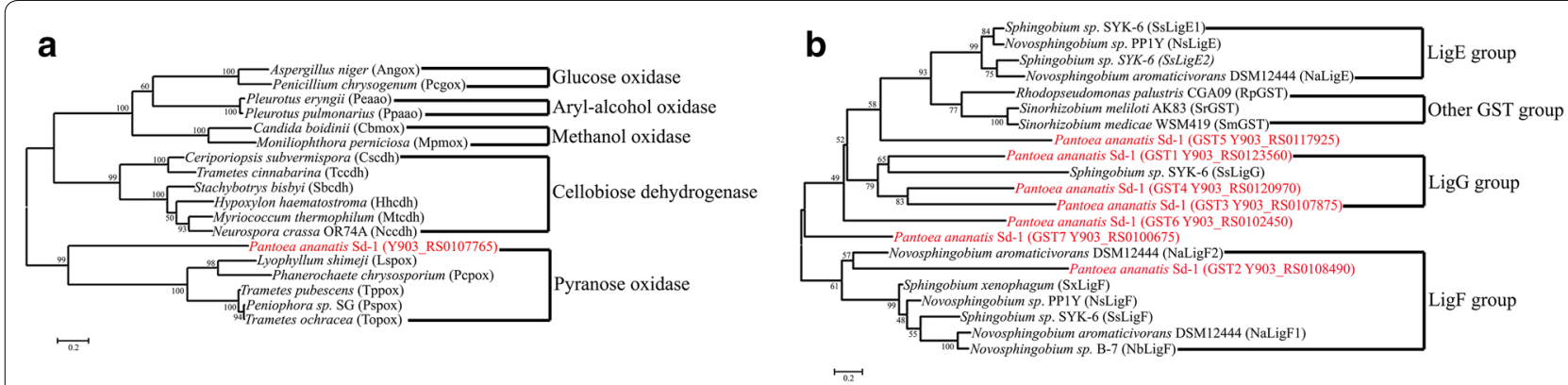

Fig. 1 Phylogenetic tree analysis of GMC family oxidoreductase $(\mathbf{a})$ and glutathione S-transferases $(\mathbf{b})$ amino acid sequences. The tree was generated by the maximum likelihood algorithm (1000 bootstrap trials) using MEGA 5.1. The scale bar represents the number of amino acid substitutions per site. The red color indicates amino acid sequences selected from P. ananatis Sd-1. Gox glucose oxidase, aao aryl-alcohol oxidase, mox methanol oxidase, cdh cellobiose dehydrogenase, pox pyranose oxidase, GST glutathione S-transferase. Angox [GeneBank: CAC12802]; Pcgox [GeneBank: AFA42947]; Peaao [GeneBank: AAC72747]; Ppaao [GeneBank: AAF31169]; Cbmox [GeneBank: AAA34321]; Mpmox [GeneBank: AFO55203]; Cscdh [GeneBank: ACF60617]; Tccdh [GeneBank: ADX41688]; Sbcdh [GeneBank: ADT70778]; Hhcdh [GeneBank: ADT70776]; Mtcdh [GeneBank: ABS45567]; Nccdh [GeneBank: EAA27355]; Lspox [GeneBank: BAD12079]; Pcpox [GeneBank: AAS93628]; Tppox [GeneBank: AAW57304]; Pspox [GeneBank: AAO13382]; Topox [AAP40332]; SsLigE [GeneBank: BAK65541]; NsLigE [GeneBank: CCA92088]; SsLigP [GeneBank: BAK67935]; NaLigE [GeneBank: ABD26841]; RpGST [GeneBank: CAE29781]; SrGST [GeneBank: AEG52712]; SmGST [GeneBank: YP_001326465]; SsLigF1 [GeneBank: BAK65540]; NsLigF1 [GeneBank: CCA92087]; SxLigF2 [GeneBank:WP_019052363]; NaLigF1 [GeneBank: ABD26530]; NbLigF1 [GeneBank:WP_022675760]; NaLigF2 [GeneBank: ABD27301]; SsLigG [GeneBank: BAK65542] 


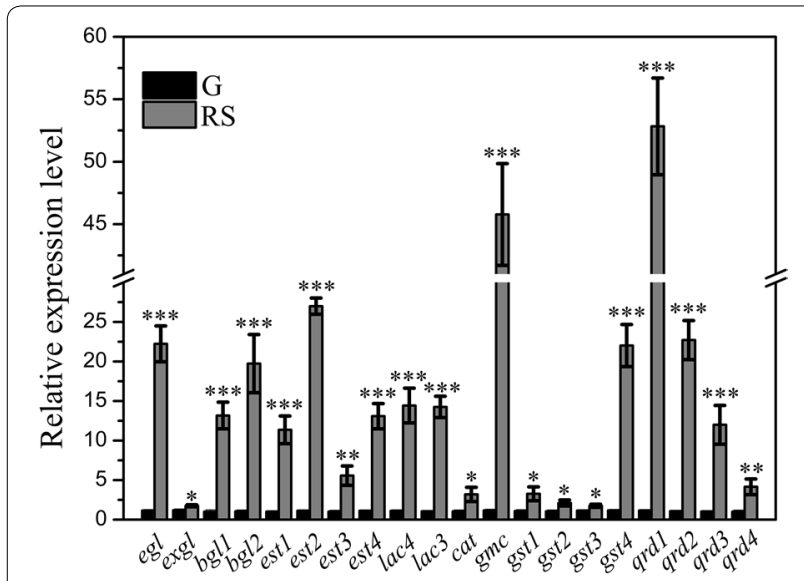

Fig. 2 Lignocellulolytic enzyme genes relative expression levels of $P$. ananatis Sd-1 in the presence of different substrates. $G$ glucose substrate, RS rice straw substrate. eg/ (Y903_RS0123720): endoglucanase, exgl (Y903_RS0108720): exoglucanase, bg/1 (Y903_RS0116520): $\beta$-glucosidase 1, bg/2 (Y903_RS0113180): $\beta$-glucosidase 2, est1 (Y903_RS0120815): esterase 1, est2 (Y903_RS0117780): esterase 2, est3 (Y903_RS0100380): esterase 3, est4 (Y903_RS0113655): esterase 4, lac4 (Y903_RS0119240): multicopper oxidase 1, lac3 (Y903_RS0111680): multicopper oxidase 2, cat (Y903_RS0115335): catalase/hydroperoxidase, gmc (Y903_RS0107765): GMC family oxidoreductase, gst1 (Y903_RS0123560): glutathione S-transferase 1, gst2 (Y903_ RS0108490): glutathione S-transferase 2, gst3 (Y903_RS0107875): glutathione S-transferase 3, gst4 (Y903_RS0120970): glutathione S-transferase 4, ard1 (Y903_RS0107980): quinone oxidoreductase 1, ard2 (Y903_RS0118595): quinone oxidoreductase 2, ard3 (Y903_ RS0110255): quinone oxidoreductase 3, qrd4 (Y903_RS0112360): quinone oxidoreductase 4 . The values represent the means of the three replicates with the standard deviation (SD). Asterisks represent significant differences from the glucose-containing medium (Statistical significance: ${ }^{*} P<0.05,{ }^{* *} P<0.01,{ }^{* *} P<0.001$ )

and glucose media, respectively (1D-PAGE gel picture was shown in Additional file 4: Figure S2). The results showed that the composition of the secreted proteins from $P$. ananatis $\mathrm{Sd}-1$ differed significantly between the two media. The molecular weights of identified proteins along with their isoelectric points (pI) were shown in Additional file 5: Figure S3. Most of pI were in the range of 5.0-10.0. In total, 108 proteins were identified in rice straw culture and only 52 proteins were identified in glucose culture (detailed results were shown in Additional file 6). Among these proteins, 17 were found to be common in both cultures (shown in Fig. 3a). The presence of a few intracellular proteins was also detected, which could be a result of cell death and/or cell lysis during incubation during secretome extraction. Similar results were also reported in previous studies [12, 26].

Identified proteins were divided into the following categories: lignocellulolytic enzyme, protease, flagellar protein, transport protein, out membrane protein, lipoprotein, hypothetical protein, and other proteins. 15 of the 108 proteins $(13.9 \%)$ in the rice straw growth proteome may be putatively associated with lignocellulose degradation, while there might be only $3(5.8 \%)$ associated with glucose grown cells (Fig. 3b). Enzymes involved in polysaccharides degradation included cellulolytic and hemicellulolytic enzymes as well as other GHs were prevalent in rice straw cultures, such as one endoglucanase (GH8) (egl Y903_RS0123720), three $\beta$-glucosidases (GH1 and GH3) (bgl1 Y903_RS0123340, bgl2 Y903_RS0113180, and bgl3 Y903_RS0103625), one exoglucanase (GH10) (exgl Y903_RS0108720) two esterases (CE10) (est1 Y903_RS0120815 and est2 Y903_RS0104455), one $\beta-\mathrm{N}-$ acetylhexosaminidase (GH3) (Y903_RS0108355), and one glycosyl hydrolase (GH33) (Y903_RS0104515). In conjunction with the incidence of carbohydrate degradative enzymes in rice straw cultures, lignin degradation relevant proteins were only represented in rice straw cultures including one catalase/hydroperoxidase
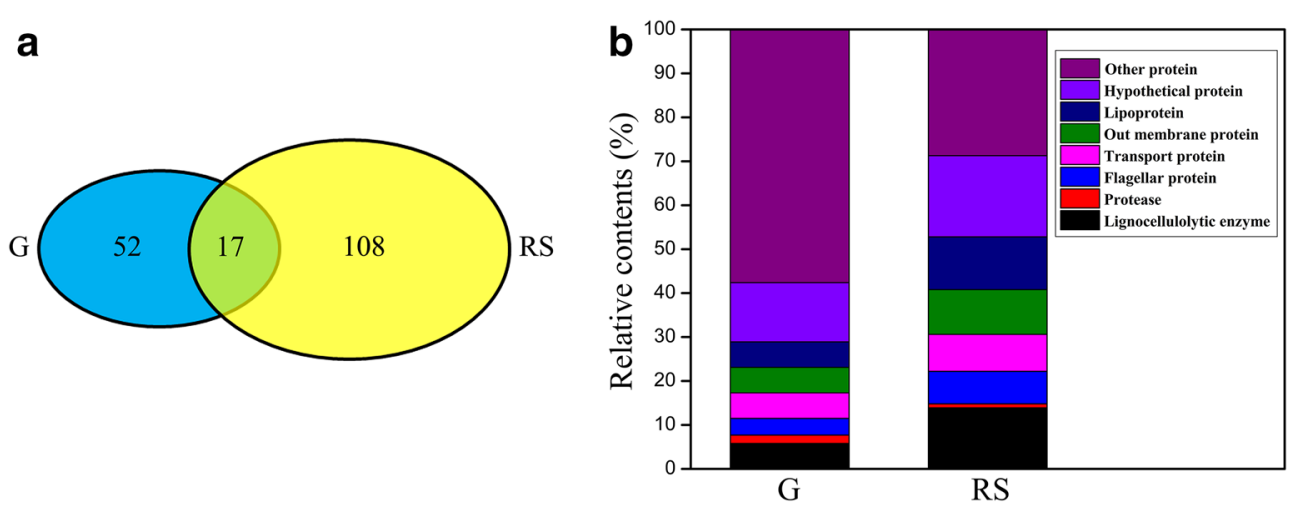

Fig. 3 Secretome identification of $P$. ananatis $S d-1$ in the presence of different substrates. a Venn diagram of the proteins identified in the $P$. ananatis Sd-1 secretome between media using rice straw (RS) and glucose substrates by nanoLC-MS/MS (G). $\mathbf{b}$ The relative contents of the various proteins identified by nanoLC-MS/MS in glucose-containing medium (G) and rice straw-containing medium (RS) 
(AA2) (cat Y903_RS0115335) and one multicopper oxidase (lac4 Y903_RS0119240) (Table 3). Among these enzymes, most possessed signal peptides, except for one $\beta$-glucosidase (Y903_RS0103625), one glycosyl hydrolase (Y903_RS0104515), and one catalase/hydroperoxidase (Y903_RS0115335). There were only three CAZymes identified in glucose cultures: one hypothetical protein (CE1) (Y903_RS0116730), one translocation protein TolB (PL22) (Y903_RS0113490), and one lysozyme (GH24) (Y903_RS0115180).

\section{Comparison of enzymes activities from $P$. ananatis Sd-1} grown on medium containing with or without rice straw

We detected several lignocellulolytic enzymes activities displayed by $P$. ananatis $\mathrm{Sd}-1$ to further confirm its degradative ability. As presented in Fig. 4, the lignin peroxidase-like activity was only detected in rice straw cultures. The activities of endoglucanase, $\beta$-glucosidase, xylanase-like, exoglucanase, and laccase-like for rice straw were significantly higher than those for glucose, especially for the first three enzymes. However, manganese peroxidase-like activity remained undetected in both cultures.

To investigate whether higher enzymes activities were caused by increases in bacterial growth or in the content of secreted proteins, $P$. ananatis $\mathrm{Sd}-1$ grew on rice straw and glucose medium were assayed. In Fig. 5a, cell density of $P$. ananatis $\mathrm{Sd}-1$ in glucose cultures was significantly higher compared to growth in rice straw cultures (at least $P<0.01$ ). Cultures grown separately on glucose and rice straw reached saturation on day 3 with the value of $9.42 \pm 0.01 \log 10 \mathrm{CFU} / \mathrm{ml}$ and $8.67 \pm 0.03 \log 10 \mathrm{CFU} /$ $\mathrm{ml}$, respectively. In contrast, the amount of secreted protein contents in rice straw was significantly higher compared to that of glucose cultures (at least $P<0.01$ ). The maximum protein contents of both cultures were reached at day 3 with the value of $1.19 \pm 0.03 \mathrm{mg} / \mathrm{ml}$ and $1.42 \pm 0.02 \mathrm{mg} / \mathrm{ml}$, respectively (Fig. 5b).

\section{Hydrolysis of rice straw by secretome of $P$. ananatis Sd-1 from rice straw culture}

To further assess the lignocellulose degrading ability, the secretome of $P$. ananatis $\mathrm{Sd}-1$ were extracted from rice straw cultures at different time intervals and evaluated for rice straw saccharification. As depicted in Fig. 6, with increased incubation, a basically increase in reducing sugar was released from rice straw. The highest yield of released reducing sugar was detected from the third day's secretome with a value of $129.11 \pm 2.7 \mathrm{mg} / \mathrm{gds}$. And the sixth day's secretome produced the least reducing sugar.

\section{Discussion}

Lignocellulose degrading microorganisms and their degradative systems possess great potential for biofuels production [27]. To date few microorganisms with the exception of white-rot fungi have been reported to have the ability to degrade cellulose, hemicellulose, and lignin, simultaneously [28]. However, currently there is no commercial product for lignocellulose biodegradation, in part due to the practical challenges of fungal enzyme expression and fungal genetic manipulation [29]. Recent work indicates that the diverse bacterial lignocellulolytic systems may be more significant than previously thought, but their degradation catabolism has not been well characterized [30, 31]. Our previous study found that the endophytic bacterium $P$. ananatis $\mathrm{Sd}-1$ had strong comprehensive ability to degrade cellulose, hemicellulose, and lignin [18]. Characterization of its degradation system will be very useful for utilization of plant lignocellulose for production of biofuels.

According to CAZy family classification, GHs, CEs, PLs, and CBMs reportedly play main roles in

Table 3 Identification of main lignocellulolytic proteins in the secretome of $P$. ananatis Sd-1 in rice straw culture

\begin{tabular}{|c|c|c|c|c|c|c|c|}
\hline Locus tag & Identified protein description & Score & Unique peptides & Peptides & Protein mass (kDa) & Isoelectric point & Signal peptides \\
\hline Y903_RS0108720 & exoglucanase & 12.84 & 5 & 5 & 41.6 & 8.72 & Y \\
\hline Y903_RS0103625 & beta-glucosidase & 12.06 & 3 & 3 & 44.2 & 5.79 & N \\
\hline Y903_RS0113180 & beta-glucosidase & 10.31 & 3 & 3 & 84 & 6.48 & Y \\
\hline Y903_RS0123340 & beta-glucosidase & 22.52 & 5 & 5 & 53.2 & 6.33 & Y \\
\hline Y903_RS0123720 & endoglucanase & 10.8 & 4 & 4 & 38.6 & 6.55 & Y \\
\hline Y903_RS0104515 & glycosyl hydrolase & 12.79 & 4 & 4 & 43.8 & 5.23 & N \\
\hline Y903_RS0104455 & esterase & 6.93 & 3 & 3 & 37.8 & 5.75 & Y \\
\hline Y903_RS0120815 & esterase & 7.74 & 2 & 2 & 33.1 & 9.60 & Y \\
\hline Y903_RS0108355 & beta-N-acetylhexosaminidase & 8.47 & 3 & 3 & 88.4 & 6.26 & Y \\
\hline Y903_RS0115335 & catalase/hydroperoxidase & 5.95 & 2 & 2 & 80 & 5.71 & $N$ \\
\hline Y903_RS0119240 & multicopper oxidase & 11.23 & 4 & 4 & 58.1 & 6.25 & Y \\
\hline
\end{tabular}



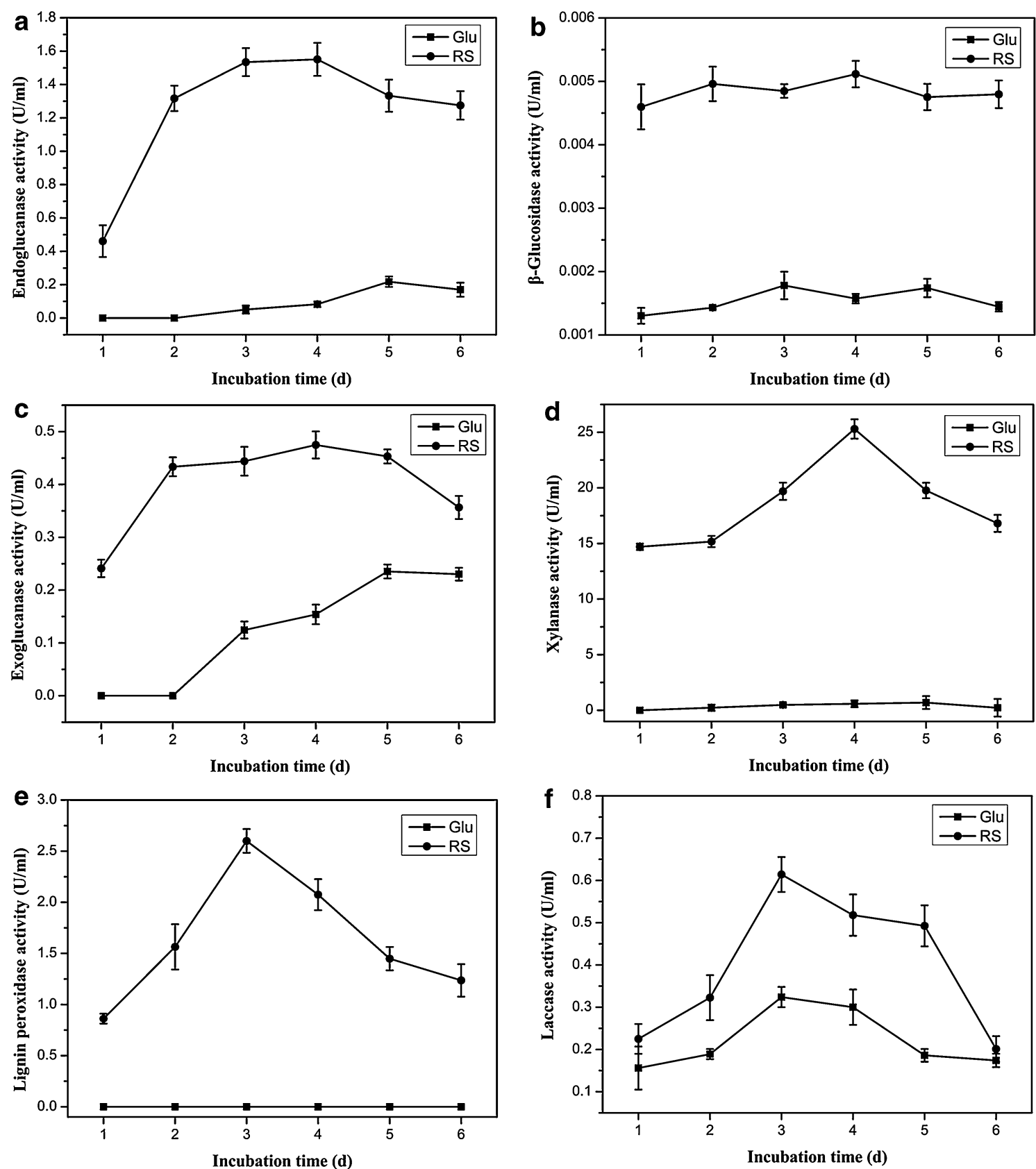

Fig. 4 Lignocellulolytic enzyme activities of $P$. ananatis $S d-1$ in the presence of different substrates. The activities of endoglucanase, $\beta$-glucosidase, exoglucanase, xylanase-like, lignin peroxidase-like, laccase-like are listed in $\mathbf{a}-\mathbf{f}$, respectively. $G$ glucose substrate, $R S$ rice straw substrate. Data are presented in triplicate from experiments as the mean standard deviation

lignocellulosic polysaccharide degradation. Similarly, it has also been reported that AAs contribute largely to lignin breakdown [32]. Bioinformatic comparisons of CAZy in P. ananatis Sd-1 to other known cellulolytic and ligninolytic bacteria as well as $P$. ananatis strains confirmed its lignocellulolytic capabilities. Moreover, the biodegradation system in $P$. ananatis $\mathrm{Sd}-1$ seems has its own characteristics.

In general, cellulose degradation is attributed to the synergistic action of three classes of glycosyl hydrolases: (1) endoglucanases, (2) exoglucanases, and (3) $\beta$-glucosidases [33]. CBM, a non-catalytic 
a

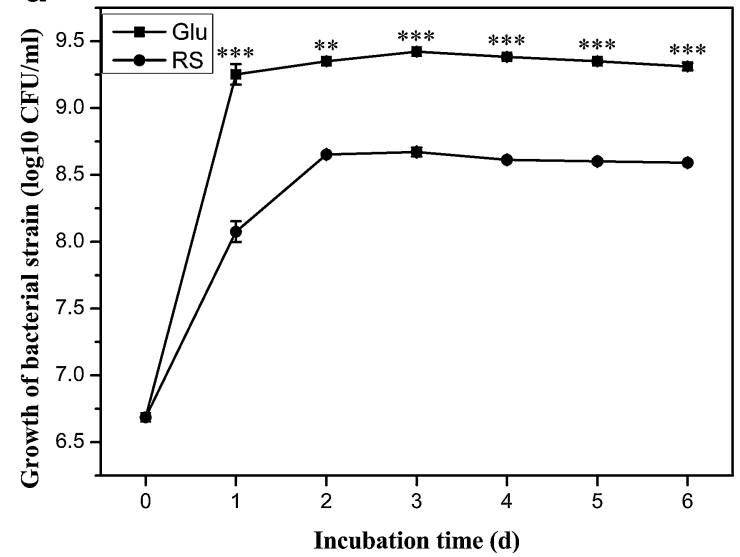

b

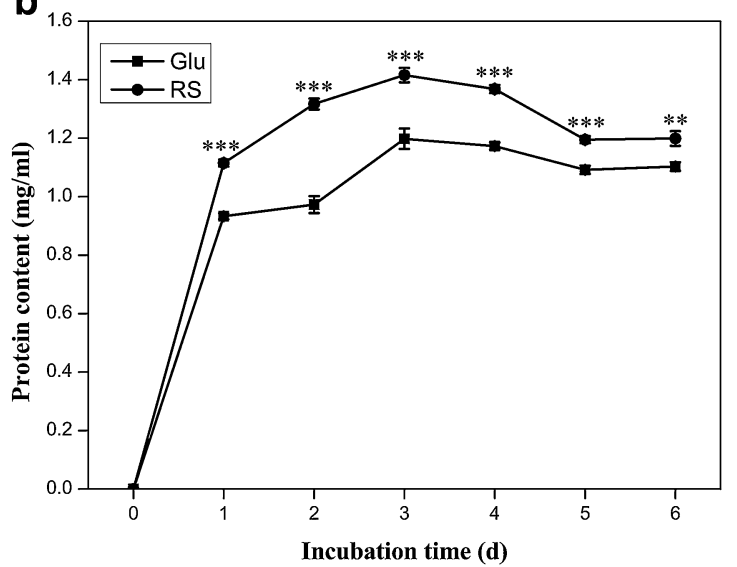

Fig. 5 Growth versus protein content of $P$. ananatis Sd-1 in the presence of different substrates. a Growth of Sd-1 in the presence of glucose and rice straw substrates. $\mathbf{b}$ Protein content produced by $\mathrm{Sd}-1$ in the presence of glucose and rice straw substrates. G glucose substrate, RS rice straw substrate. Data are presented in triplicate from experiments as the mean standard deviation. Asterisks represent significant differences from the glucose-containing medium (Statistical significance: ${ }^{*} P<0.05,{ }^{* *} P<0.01,{ }^{* * *} P<0.001$ )

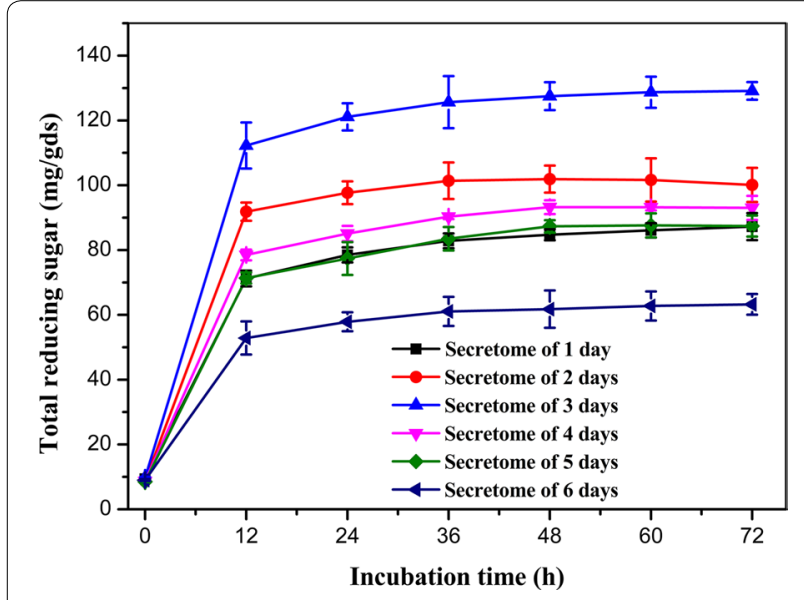

Fig. 6 Reducing sugar released from rice straw by the enzymatic hydrolysis of $P$. ananatis $\mathrm{Sd}-1$ secretome. Secretome of $P$. ananatis Sd-1 secretome was extracted from rice straw cultures at every 24-h interval

polysaccharide-recognizing module possessed by some GHs, influences enzymes activities by attaching to the substrate [34]. We found that only five GHs containing CBM domains in $P$. ananatis Sd- 1 . The value is far less than that reported in C. bescii DSM 6725 (14) and C. thermocellum ATCC 27405 (38). C. thermocellum ATCC 27405 is a typical cellulosome production strain [35], which might contain multiple CBM domains for cellulose substrates attachment. Its cellulosome subunits have been identified by the proteomic analysis [8]. Caldicellulosiruptor bescii genus are well-studied multifunctional enzymes production strains. Their multifunctional enzymes generally contain one or several CBMs [36]. Correspondingly, a group of glycosidases with CBM3 domains have been identified in the secretome of $C$. bescii when grown on crystalline cellulose. This implied that their enzymes might exist as free enzymes or are incorporated into cellulosomes [37]. In contrast, $P$. ananatis $\mathrm{Sd}-1$ possesses typical cellulase genes encoding endoglucanase, $\beta$-glucosidase, and exoglucanase lacking CBM domains. Upon comparison of expression levels, we found that transcripts of all detected genes encoding these enzymes were significantly up-regulated in $P$. ananatis $\mathrm{Sd}-1$ cultured in rice straw-containing medium (at least $P<0.05$ ). Higher activities of these enzymes were also all detected in the supernatant of rice straw cultures relative to those in glucose cultures. Correspondingly, we found that endoglucanase (egl), exoglucanase (exgl), and two $\beta$-glucosidase enzymes ( $b g l 1$ and $b g l 2)$ all contain signal peptides. These four enzymes as well as another $\beta$-glucosidases (Bgl3) could only be identified in supernatant of rice straw cultures. These evidences indicate that the cellulase systems in $P$. ananatis $\mathrm{Sd}-1$ might be composed of free single enzymes, which are soluble and diffuse away from the cell under culture conditions.

Several enzymes, including xylanases and esterases, are needed to completely degrade the hemicellulose polysaccharides [38]. No typical xylanase gene was found, but it was noticed that the CEs number (25) present in $P$. ananatis Sd-1 are strikingly higher than that of all the compared strains, including other eight $P$. ananatis strains. There are nine esterases belonging to CEs in P. ananatis Sd-1: Ets1 Y903_RS0120815 and est2 Y903_RS0117780 belonging to the CE10 family 
shared 85 and $75 \%$ similarity with the endo-1,4-betaxylanase (GenBank: CRH34589.1) and xynB (GenBank: WP_052270754), respectively. Both sequences of the two proteins contain signal peptides. Members of CE10 have been found to possess both carboxylesterase and xylanase activities [39]. In addition, two enzymes from CE10 have been identified in the secretome of Penicillium purpurogenum when it was cultured with acetylated xylan substrates [40]. Consistent with these reports, in P. ananatis $\mathrm{Sd}-1$, the transcript levels of four detected esterase genes including est 1 and est 2 were significantly up-regulated (at least $P<0.01$ ) in rice straw cultures, which corresponded with high xylanase-like activity detected in the same cultures. It should be mentioned that the maximum xylanase-like activity reached $25.29 \pm 0.87 \mathrm{U} / \mathrm{ml}$ in rice straw cultures, which is higher than that was previously reported for cellulolytic fungus [26]. Furthermore, two esterases including est 2 were only detected in rice straw cultures. These results are consistent with the previous reports, which indicated that $P$. ananatis $\mathrm{Sd}-1$ might possess additional enzymes for efficient breakdown of hemicellulose and further characterization of these enzymes might broaden existing knowledge of hemicellulose degradation system. Interestingly, no CE10 was found in the eight other compared $P$. ananatis strains, except for typical xylanase genes. The difference between $P$. ananatis Sd-1 and other $P$. ananatis strains might be attributed to an evolutionary adaption of $P$. ananatis $\mathrm{Sd}-1$ to the endophytic environment, which was different with that of other compared $P$. ananatis strains [21, 41].

Rice straw saccharification by the $P$. ananatis $\mathrm{Sd}-1$ secretome from rice straw cultures confirmed the existence of its lignocellulosic polysaccharides degradation system. The highest yield of released reducing sugars was attained from the third day's secretome, whereas the lowest yield was observed from the sixth day's secretome. These were approximately consistent with results of enzymes activities detection. Analyses indicated that the secretome of $P$. ananatis $\mathrm{Sd}-1$ release higher amounts of reducing sugars than that reported for Phoma exigua secretome which used pretreated paddy straw or wheat straw as substrates $[42,43]$. These indicated that $P$. ananatis $\mathrm{Sd}-1$ is deserved an in-depth exploration for its enzyme system, such as GHs and CEs.

Although bacterial enzymes associated with lignin degradation are not well characterized in comparison to their fungal counterparts, it has been reported that bacteria have their own unique enzymes for lignin degradation, e.g., $C \alpha$-dehydrogenase $(\operatorname{Lig} \mathrm{D})$, glutathionedependent $\beta$-etherase enzymes ( $\operatorname{LigE}, \mathrm{F}, \mathrm{G})$, demethylase enzyme ( $\operatorname{LigX}$ ), and DyP-type peroxidases [30, 44-46]. Hence it is not surprising that there is no classic fungi lignin degradation enzyme in genome of $P$. ananatis
Sd-1. Recent reports of multicopper oxidases demonstrating laccase activities have increased [47, 48]. Secreted catalase/hydroperoxidase, which possess similar heme-containing domains to lignin peroxidases, is associated with strong peroxidase activity and was shown to play an important role in the lignin degradation process in E. lignolyticus SCF1 [25]. In P. ananatis Sd-1, significantly up-regulated transcript levels of 2 multicopper oxidase genes $(P<0.001)$ and catalase/hydroperoxidase gene $(P<0.05)$ were found to corresponded with higher laccase-like and lignin peroxidase-like activities in rice straw cultures relative to glucose cultures. These results suggest that these enzymes might fulfill similar roles to laccase and lignin peroxidase, respectively, in $P$. ananatis Sd-1. Notably, the maximum value $(2.59 \pm 0.11 \mathrm{U} / \mathrm{ml})$ for lignin peroxidase-like activity produced by $P$. ananatis $\mathrm{Sd}-1$ in rice straw culture exceeds previously reported values for any fungus or bacterium $[49,50]$. Furthermore, the identification of multicopper oxidase (lac4) and catalase/hydroperoxidase (cat) proteins among secretome of rice straw cultures provides supporting evidence. These data provide a catalog of novel bacterial enzymes participating in the deconstruction of lignin. Indeed, we have cloned one multicopper oxidase gene lac4 (Y903_RS0119240) and the recombinant enzyme can efficiently degrade lignin and decolorize dyes in vitro [51].

During fungal degradation of lignin, GMC family oxidoreductases such as glucose oxidase, aryl-alcohol oxidase, methanol oxidase, and pyranose oxidase were reported to participate by providing the hydrogen peroxide required by ligninolytic peroxidases [52, 53]. According to our phylogenetic analysis, the pyranose oxidase enzyme might be the GMC family oxidoreductase equivalent in $P$. ananatis $\mathrm{Sd}-1$. In addition, hydrogen peroxide production is a typical character in the Fenton chemistry pathway. Quinone oxidoreductases were found to drive Fenton chemistry systems participated in lignin degradation in the brown-rot fungus Gloeophyllum trabeum [54]. Interestingly, transcript levels of the GMC family oxidoreductase and quinone oxidoreductases in $P$. ananatis Sd-1 were all significantly up-regulated in rice straw cultures relative to glucose cultures (at least $P<0.01$ ). These data provide clues that the Fenton chemistry pathway might also exist in bacteria, although this process was shown previously to only exist in fungi. Further research in support of this hypothesis is currently underway.

In our study, it was surprisingly to find that there are nine AAs in $P$. ananatis Sd-1, while they are absent from the other compared strains except for one. Considering their supposed role in lignin degradation [32], the enzyme system in $P$. ananatis Sd-1 might be a new resource for lignin decomposition. Although in this study, we only confirmed two AAs (AA2-Catalase/hydroperoxidase and 
AA3-GMC family oxidoreductase) were related to lignin degradation, we cannot exclude the possibility that other $P$. ananatis $\mathrm{Sd}-1 \mathrm{AAs}$ are lignin degradation relevant enzymes. This speculation cannot be verified due to the limited reference information presently available.

Possessing unique enzymes for lignin degradation is an attractive characteristic in a bacterial degradative system. For example, GSTs (LigE, F, G) are able to cleave the $\beta$-aryl ether in Sphingomonas paucimobilis SYK-6 [44]. According to phylogenetic analysis, four GST genes in $P$. ananatis $\mathrm{Sd}-1$ might possess $\beta$-etherase activity. Transcript levels of these four GST genes were significantly up-regulated when rice straw was used as substrate (at least $P<0.05)$. It was not surprising that GST remained undetected in the secretome of $P$. ananatis $\mathrm{Sd}-1$, as none of the four GSTs possesses signal peptides. This is consistent with a report of GSTs in Sphingomonas paucimobilis SYK-6 [44]. Our results suggested that a distinct bacteria $\beta$-aryl ether degradation pathway might also exist for lignin degradation by $P$. ananatis $\mathrm{Sd}-1$.

Our results confirmed that microbial lignocellulolytic enzymes production is dependent on the carbon source [11]. Growth comparisons of $P$. ananatis Sd-1 in different media indicted poorer growth in rice straw compared to glucose. However, the secreted protein contents from rice straw cultures were higher. These indicated that the discrepancy in enzymes activities was not related to cell density, but rather differences in gene expression in response to the carbon sources.

According to the work in this paper, further studies should focus on the individual enzyme function to aid in development of efficient biological treatment schemes. Elucidation of the mechanistic features of $P$. ananatis $\mathrm{Sd}-1$ lignocellulolytic system is also indispensable for its further biotechnological application.

\section{Conclusions}

This study confirms the strong lignocellulosic biomass degradation capacity of rice endophytic bacterium $P$. ananatis $\mathrm{Sd}-1$. Genomic analysis revealed that $P$. ananatis $\mathrm{Sd}-1$ possesses abundant lignocellulolytic enzymes genes, especially for ligninolytic enzymes relevant genes compared to other cellulolytic and ligninolytic bacteria. A part of these genes transcript levels were found to be highly up-regulated when induced by lignocellulosic substrates, which was corroborated by the secretomic and enzyme activity profiles. In addition, the secretome of $P$. ananatis $\mathrm{Sd}-1$ showed strong saccharification ability toward rice straw. Furthermore, we conclude that the cellulase system of $P$. ananatis $\mathrm{Sd}-1$ might function as free single enzymes. The $\beta$-aryl ether degradation and Fenton chemistry pathways might exist in lignin degradation process of $P$. ananatis $\mathrm{Sd}-1$. The discovery of lignocellulolytic system in $P$ ananatis $\mathrm{Sd}-1$ is crucial for a deeper understanding of its degradation mechanisms and the regulation of their extracellular proteins. This work and further evaluation will therefore be a cornerstone for future applications of $P$. ananatis $\mathrm{Sd}-1$ in biofuels production.

\section{Methods}

\section{Bacterial strains and growth media}

The P. ananatis Sd-1 (China General Microbiological Culture Collection Centre, no. 6698) is an endophytic bacterium isolated from rice seed in Changsha city of Hunan Province, China [18]. P. ananatis Sd-1 colonies were inoculated in Luria-Bertani (LB) broth medium and incubated until the logarithmic growth phase at $30{ }^{\circ} \mathrm{C}$ with shaking at $170 \mathrm{rpm}$. Then $1 \mathrm{ml}$ culture was inoculated into triplicate $100 \mathrm{ml}$ sterile rice straw (pretreated as previously described [18]) or glucose-containing mineral salt media (10.0 g rice straw or glucose, $2.0 \mathrm{~g}$ $\left(\mathrm{NH}_{4}\right)_{2} \mathrm{SO}_{4}, 1.0 \mathrm{~g} \mathrm{KH}_{2} \mathrm{PO}_{4}, 1.0 \mathrm{~g} \mathrm{KH}_{2} \mathrm{PO}_{4}, 0.2 \mathrm{~g} \mathrm{MgSO}_{4}$, $0.1 \mathrm{~g} \mathrm{CaCl}_{2}, 0.02 \mathrm{~g} \mathrm{MnSO}_{4}$, and $0.05 \mathrm{~g} \mathrm{FeSO}_{4}$ in $1000 \mathrm{ml}$ distilled water, $\mathrm{pH}$ 7.2) and incubated for 6 days at $30{ }^{\circ} \mathrm{C}$ with shaking at $170 \mathrm{rpm}$.

\section{Bacterial strain growth measurement}

To assess growth of bacteria in rice straw or glucose-containing media, $1 \mathrm{ml}$ samples were periodically withdrawn at $24 \mathrm{~h}$ intervals and serially diluted (up to $10^{-7}$ ) were proceeded with sterile $0.8 \%(w / v)$ normal saline. Thereafter, $1 \mathrm{ml}$ diluted sample was placed on LB medium and spread over the agar surface, and incubated at $30^{\circ} \mathrm{C}$ for $24 \mathrm{~h}$. Cell counts were performed on plates containing between 30 and 300 colonies. Results were calculated as $\log 10 \mathrm{CFU} / \mathrm{ml}$. All assays were performed with three replicates.

\section{Enzyme assays}

A total of $2 \mathrm{ml}$ samples were withdrawn from rice straw and glucose cultures periodically at every 24-h interval for lignocellulolytic enzyme activity assays. Endoglucanase and exoglucanase activities were determined according to the method of Ghose using $1 \%(w / v)$ sodium carboxymethyl cellulose and Whatman grade 1 filter paper as substrates, respectively [55]. Xylanase-like activity was assayed as described by the method of Bailey et al. using beechhood xylan as substrate [56]. Released reducing sugar from the reaction were determined by the 3,5-dinitrosalicylic acid (DNS) method [57] using glucose or xylose as standard. One unit of enzyme activity was defined as the amount of enzyme that catalyzes the release of $1 \mu \mathrm{mol}$ reducing sugar as glucose or xylose equivalent per minute under the specified assay conditions. The $\beta$-glucosidase activity was assayed as described 
by Parry et al. [58] using $10 \mathrm{mM} p$-nitrophenyl- $\beta$-Dglucopyranoside as substrate. The reaction was terminated by adding $100 \mu \mathrm{l} 1 \mathrm{M} \mathrm{Na}_{2} \mathrm{CO}_{3}$ and the color developed was measured at $405 \mathrm{~nm}$. One unit of enzyme activity was defined as the amount of enzyme required to release $1 \mu \mathrm{mol} p$-nitrophenol per minute under the conditions of the assay.

Lignin peroxidase-like activity was measured according to the method of Shi et al. by monitoring oxidation of veratryl alcohol to veratraldehyde at $310 \mathrm{~nm}$ $\left(\varepsilon 310=9300 \mathrm{~mol}^{-1} \mathrm{~cm}^{-1}\right)$ [59]. Laccase-like activity was measured according to the method of Nakagawa et al. by monitoring oxidation of 2,2,-azino-bis (3-ethylbenzothiazoline-6-sulfonic acid) (ABTS) to ABTS radical at $420 \mathrm{~nm}\left(\varepsilon 420=36000 \mathrm{~mol}^{-1} \mathrm{~cm}^{-1}\right)$ [60]. The manganese peroxidase-like activity was measured by monitoring oxidation of 2,6-dimethyl phenol (2,6-DMP) to coerulignone at $469 \mathrm{~nm}\left(\varepsilon 469=49,600 \mathrm{~mol}^{-1} \mathrm{~cm}^{-1}\right)$ [59]. One unit of lignin peroxidase-like or laccase-like or manganese peroxidase-like activity was defined as the amount of enzyme needed to produce $1 \mu \mathrm{mol}$ product per minute. All assays were performed with three replicates.

Genome sequencing and analysis of Pantoea ananatis Sd-1 Genomic DNA of $P$. ananatis $\mathrm{Sd}-1$ was extracted from an overnight culture in LB broth medium using a GeneRay Bacterial Genomic DNA Extraction Kit (GeneRay, Shanghai, China). The genome of $P$. ananatis $\mathrm{Sd}-1$ was sequenced at Novogene Bioinformatics Technology Co., LTD (Beijing, China) using Illumina Hiseq 2000, with a shotgun library of 500 bp insertion size. Prediction and annotation of genes were performed using the Prodigal (Prokaryotic Dynamic Programming Genefinding Algorithm). Functional annotation was performed by BLASTP algorithm using the public database KEGG, NR, TrEMBL, and SWISS-PROT. The complete genome sequence of $P$. ananatis $\mathrm{Sd}-1$ was deposited at DDBJ/EMBL/GenBank under the accession number AZTE00000000. Genes related to CAZy were performed using the dbCAN CAZyme annotation program from dbCAN pipelines (http://csbl.bmb.uga.edu/ dbCAN/index.php) [61] against the Carbohydrate-Active Enzymes database (http://www.cazy.org/) [62]. The output from dbCAN was parsed using the following cutoff values: if alignment length $>80 \mathrm{aa}$, using E-value $<1 \mathrm{e}^{-5}$, otherwise using E-value $<1 \mathrm{e}^{-3}$. Signal peptides prediction was performed by SignalP v4.0 [63]. The compared CAZy of strains were obtained from CarbohydrateActive Enzymes database and various references except the 4 partially assembled genomes strains: $P$. ananatis B1-9 [GenBank: CAEJ00000000], P. ananatis LMG 2665 [GenBank: JMJJ00000000], P. ananatis PA4 [GenBank: JMJK00000000], and P. ananatis BD442 [GenBank:
JMJL00000000]. After annotation of genes from those four strains genomes, CAZyme annotation of them was performed as previously mentioned.

\section{Total RNA isolation and CDNA synthesis}

Total RNA was extracted from the cells of $P$. ananatis Sd-1 collected from rice straw and glucose-containing medium at the third day using TRIzol reagent (Invitrogen, Carlsbad, CA, USA) according to the manufacturer's specifications.

Reverse transcription was performed using PrimeScript RT reagent Kit (Perfect Real Time) (Takara, Dalian, China) according to the manufacturer's instructions.

\section{Quantitative real-time PCR}

The primers (Additional file 7: Table S3) used for qRTPCR in this study were designed by Beacon Designer 7.7 software. The qRT-PCR reactions were performed on Mx3000P thermal cycler (Stratagene, Santa Clara, CA) and were normalized using 16S rRNA expression levels as internal reference. Reactions were conducted using SYBR $^{\circledR}$ Premix Ex Taq ${ }^{\mathrm{TM}}$ II (Tli RnaseH Plus) (Takara, Dalian, China). The applied cycling conditions were as follows: initial denaturation at $95^{\circ} \mathrm{C}$ for $30 \mathrm{~s}$, followed by 40 cycles of $95^{\circ} \mathrm{C}$ for $5 \mathrm{~s}$, then $60^{\circ} \mathrm{C}$ for $30 \mathrm{~s}$, and $72^{\circ} \mathrm{C}$ for $30 \mathrm{~s}$. At the end of the amplification of reaction, dissociation curves were performed to verify primer specificity. All reactions were performed in triplicate. Relative transcript levels were determined by the $2^{-\Delta \Delta \mathrm{Ct}}$ method [64]: normalizing the gene expression levels in rice straw-containing medium to that in glucose-containing medium, where expression level of the gene in glucose-containing medium was set to one.

\section{Total secretome protein extraction}

Cultures of $P$. ananatis $\mathrm{Sd}-1$ grew in rice straw and glucose-containing media were harvested at every 24-h interval. After filtering, cells and supernatant were separated by centrifugation $\left(4000 \mathrm{rpm}, 10 \mathrm{~min}, 4{ }^{\circ} \mathrm{C}\right.$ ) and further clarified by filtration through $0.2 \mu \mathrm{m}$ membranes (Millipore corporation, Billerica, MA). The supernatant protein fraction was concentrated using acetone precipitation [42]. The precipitate protein pellets were dissolved in an appropriate volume of citrate buffer $(50 \mathrm{mM}$, $\mathrm{pH} 4.8$ ) and used for the saccharification of rice straw. For identification of the secretome protein, the supernatant protein fraction of the third day was precipitated with $10 \%(w / v)$ trichloroacetic aid overnight at $4{ }^{\circ} \mathrm{C}$ and collected by centrifugation $\left(10,000 \mathrm{rpm}, 30 \mathrm{~min}, 4{ }^{\circ} \mathrm{C}\right)$. The resulting protein pellets were washed three times with $96 \%$ ethanol $(v / v)$ and then dried. Protein pellets were resuspended in a sample preparation solution containing $8 \mathrm{M}$ urea, $4 \%(w / v)$ 3-[(3-cholamidopropyl) 
dimethylammonio] propanesulfonate (CHAPS), $40 \mathrm{mM}$ dithiothreitol (DTT). Protein concentrations were determined with the Non-Interference Protein Assay Kit (Sangon Biotech, Shanghai, China).

\section{Saccharification of rice straw by secretome of $P$. ananatis Sd-1}

Saccharification of pretreated rice straw was carried out in screw-capped plastic bottles containing $10 \%$ substrate $(w / v)$ and secretome of $P$. ananatis Sd-1 with $0.01 \%$ sodium azide. Saccharification was carried out at $50{ }^{\circ} \mathrm{C}$ with shaking at $150 \mathrm{rpm}$ for $72 \mathrm{~h}$. Samples were withdrawn at every 12- intervals for total reducing sugars assay. The yield of released reducing sugar was expressed as $\mathrm{mg}$ per gram of dry solid cell mass ( $\mathrm{mg} / \mathrm{gds}$ ).

\section{Secretome protein identification}

Twenty-five micro gram of protein samples from each treatment were loaded into a $12 \%$ SDS-polyacrylamide gel for electrophoresis. After destaining, each sample lane was horizontally dissected into 16 fractions and further excised into $1 \mathrm{~mm}^{2}$ pieces.

Protein digestion and peptide extraction were performed according to Andreji et al. [65]. Gel fragments were washed once with $50 \%(v / v)$ methanol and destained twice for $30 \mathrm{~min}$ in acetonitrile $50 \%(v / v)$ with $25 \mathrm{mM}$ ammonium bicarbonate. Then incubated with $10 \mathrm{mM}$ DTT in $25 \mathrm{mM}$ ammonium bicarbonate at $56{ }^{\circ} \mathrm{C}$ for $1 \mathrm{~h}$ and subsequently incubated with $55 \mathrm{mM}$ iodoacetamide in the dark at room temperature for $45 \mathrm{~min}$. Thereafter, gel fragments were digested for $18 \mathrm{~h}$ at $37^{\circ} \mathrm{C}$ with $12 \mathrm{ng} / \mu \mathrm{l}$ sequencing grade modified trypsin (Promega, Madison, USA) dissolved in $25 \mathrm{mM}$ ammonium bicarbonate and $10 \%(v / v)$ acetonitrile solution. Following trypsin digestion, extraction solution containing $66.7 \%$ acetonitrile and $5 \%$ formic acid was added and incubated with sonication for $15 \mathrm{~min}$. Peptides were collected from the extraction solution, dried by vacuum centrifugation, and resuspended in $0.1 \%$ formic acid solution for mass spectrometric analysis.

Samples were analyzed with two technical repetitions each. NanoLC-MS/MS analysis was performed using an EASY-nano LC system (Proxeon Biosystems, Odense, Denmark) coupled online with an LTQ-Orbitrap Velos mass spectrometer (Thermo Scientific, Waltham, MA). Peptides were loaded onto a PepMap C18 trap column $(75 \mu \mathrm{m}, 15 \mathrm{~cm})$ (Dionex corporation, Sunnyvale, CA) and eluted using a gradient from $100 \%$ solvent A $(0.1 \%$ formic acid) to $35 \%$ solvent B ( $0.1 \%$ formic acid, $100 \%$ acetonitrile) for $38 \mathrm{~min}, 35-90 \%$ solvent $\mathrm{B}$ for $15 \mathrm{~min}$, and $100 \%$ solvent B for $5 \mathrm{~min}$ (a total of $65 \mathrm{~min}$ at $200 \mathrm{~nL} /$ min). After each run, the column was washed with $90 \%$ solvent $\mathrm{B}$ and re-equilibrated with $5 \%$ solvent A. Mass spectra were acquired in positive ion mode applying data-dependent automatic survey MS scan and MS/MS acquisition modes. Each MS scan in the Orbitrap analyzer (mass range $=\mathrm{m} / \mathrm{z} 350-2000$, resolution $=60,000$ ) was followed by MS/MS of the seven most intense ions in the LTQ. Fragmentation in the LTQ was performed by high-energy collision-activated dissociation, and selected sequenced ions were dynamically excluded for $30 \mathrm{~s}$. The raw data were viewed in Xcalibur (version 2.1, Thermo Scientific, Waltham, MA), and data processing was performed using Proteome Discoverer (version 1.3 beta, Thermo Scientific, Waltham, MA). The raw files were submitted to a database search using Proteome Discoverer with an in-house sequence algorithm against all predicted CDS of $P$. ananatis Sd-1 described above. The searches were performed with the following parameters: MS accuracy, $10 \mathrm{ppm}$; MS/MS accuracy, $0.05 \mathrm{Da}$; two missed cleavage sites allowed; carbamidomethylation of cysteine as a fixed modification; and oxidation of methionine as variable modifications. A minimum of two peptides per protein was accepted for identification. The identification lists from technical repetitions were merged, and repeated protein groups were removed.

\section{Additional files}

Additional file 1: Table S1. Genome features of Pantoea ananatis Sd-1. pdf.

Additional file 2: Table S2. Carbohydrate-active enzymes identified in the Pantoea ananatis Sd-1 genome.xIsx.

Additional file 3: Figure S1. GHs contained multiple CBM domains in genome of $P$. ananatis Sd-1. Blue colors represented linker.png.

Additional file 4: Figure S2. 1D-PAGE of proteomes of $P$. ananatis $\mathrm{Sd}-1$ grew on rice straw-containing medium (RS) and glucose-containing medium (G).png

Additional file 5: Figure S3. Molecular weight and isoelectric focussing of identified proteins. G, proteins identified in the supernatant of glucose-containing medium; RS, proteins identified in the supernatant of rice straw-containing medium. Both the molecular weight and isoelectric point were theoretical obtained from the Proteome Discoverer v.1.3 beta (Thermo Scientific) prediction during the proteins identification.png.

Additional file 6. The identified proteins in proteomes induced by rice straw and glucose substrates.xIsx.

Additional file 7: Table S3. Primers used for quantitative real-time PCR in this study.xIsx.

\section{Abbreviations}

CAZy: carbohydrate-active enzymes; CDS: protein coding sequences; GHs: glycoside hydrolases; GTs: glycosyltransferases; CEs: carbohydrate esterases; CBMs: carbohydrate bingding modules; AAs: auxillary activities; PLs: polysaccharide lyases; GMC: glucose-methanol-choline; GST: glutathione S-transferase; qRT-PCR: quantitative real-time polymerase chain reaction; nanoLC-MS/MS: nano liquid chromatography-tandem mass spectrometry; pl: isoelectric points; LB: Luria-Bertani; CFU: colony forming units; VA: veratryl alcohol; ABTS: 2,2,-azino-bis(3-ethylbenzothiazoline-6-sulfonic acid); DNS: 3,5-dinitrosalicylic acid; 2,6-DMP: 2,6-dimethyl phenol; DTT: dithiothreitol; CHAPS: 3-[(3-cholamidopropyl) dimethylammonio] propanesulfonate. 


\section{Authors' contributions}

JSM designed the experiment; carried out the genomic analysis, proteins extraction, proteins identification, and saccharification experiments; collected and analyzed the results; and drafted the manuscript. KKZ carried out the enzyme production, the enzymatic activity assay, and qRT-PCR experiments and helped to revise the manuscript. HDL participated in the design of the study, carried out bacterial strain growth measurement, and helped to draft the manuscript. YHZ provided the original idea, performed the statistical analysis, and drafted the manuscript. XML conceived the study, contributed to enzymatic activity results analysis, and helped to draft the manuscript. SBH participated in the genomic analysis and helped to revise the manuscript. XWS participated in the proteins extraction experiment and helped to revise the manuscript. JLL performed the nanoLC-MS/MS experiments and helped to revise the manuscript. BL performed the identification proteins data analysis and helped to revise the manuscript. TX participated in the design of the study and coordination and helped to revise the manuscript. CYT participated in the saccharification experiment and helped to revise the manuscript. All authors read and approved the final manuscript.

\section{Author details}

${ }^{1}$ Hunan Province Key Laboratory of Plant Functional Genomics and Developmental Regulation, College of Biology, Hunan University, Changsha 410008, Hunan, People's Republic of China. ${ }^{2}$ Department of Genetics, Institute for Plant Biotechnology, Stellenbosch University, Private Bag X1, Matieland, Stellenbosch 7602, South Africa. ${ }^{3}$ State Key Laboratory of Chemo/Biosensing and Chemometrics, College of Biology, Hunan University, Changsha 410008, Hunan, People's Republic of China. ${ }^{4}$ DNA Sequencing Unit, Central Analytical Facility, Stellenbosch University, Private Bag X1, Matieland, Stellenbosch 7602, South Africa.

\section{Acknowledgements}

This work is financially supported by the National Natural Science Foundation of China (51378191).

\section{Competing interests}

The authors declare that they have no competing interests.

Received: 9 August 2015 Accepted: 14 January 2016

Published online: 02 February 2016

\section{References}

1. Demain AL. Biosolutions to the energy problem. J Ind Microbiol Biotechnol. 2009;36(3):319-32. doi:10.1007/s10295-008-0521-8.

2. Jørgensen $\mathrm{H}$, Kristensen JB, Felby C. Enzymatic conversion of lignocellulose into fermentable sugars: challenges and opportunities. Biofuels Bioprod Bioref. 2007;1(2):119-34. doi:10.1002/bbb.4.

3. Bugg TD, Ahmad M, Hardiman EM, Rahmanpour R. Pathways for degradation of lignin in bacteria and fungi. Nat Prod Rep. 2011;28(12):1883-96. doi:10.1039/c1np00042j.

4. Lynd LR, Weimer PJ, van ZyI WH, Pretorius IS. Microbial cellulose utilization: fundamentals and biotechnology. Microbiol Mol Biol Rev. 2002;66(3):506-77. doi:10.1128/mmbr.66.3.506-577.2002.

5. Pandey S, Singh S, Yadav AN, Nain L, Saxena AK. Phylogenetic diversity and characterization of novel and efficient cellulase producing bacterial isolates from various extreme environments. Biosci Biotechnol Biochem. 2013;77(7):1474-80. doi:10.1271/bbb.130121.

6. Woo HL, Hazen TC, Simmons BA, DeAngelis KM. Enzyme activities of aerobic lignocellulolytic bacteria isolated from wet tropical forest soils. Syst Appl Microbiol. 2014;37(1):60-7. doi:10.1016/j.syapm.2013.10.001.

7. Dam P, Kataeva I, Yang SJ, Zhou F, Yin Y, Chou W, et al. Insights into plant biomass conversion from the genome of the anaerobic thermophilic bacterium Caldicellulosiruptor bescii DSM 6725. Nucleic Acids Res. 2011;39(8):3240-54. doi:10.1093/nar/gkq1281.

8. Raman B, Pan C, Hurst GB, Rodriquez M Jr, McKeown CK, Lankford PK, et al. Impact of pretreated switchgrass and biomass carbohydrates on Clostridium thermocellum ATCC 27405 cellulosome composition: a quantitative proteomic analysis. PLoS One. 2009;4(4):e5271. doi:10.1371/journal. pone.0005271.
9. Book AJ, Lewin GR, McDonald BR, Takasuka TE, Doering DT, Adams AS, et al. Cellulolytic Streptomyces strains associated with herbivorous insects share a phylogenetically linked capacity to degrade lignocellulose. Appl Environ Microbiol. 2014;80(15):4692-701. doi:10.1128/AEM.01133-14.

10. Chen S, Wilson DB. Proteomic and transcriptomic analysis of extracellular proteins and mRNA levels in Thermobifida fusca grown on cellobiose and glucose. J Bacteriol. 2007;189(17):6260-5. doi:10.1128/JB.00584-07.

11. Adav SS, Ng CS, Arulmani M, Sze SK. Quantitative iTRAQ secretome analysis of cellulolytic Thermobifida fusca. J Proteome Res. 2010;9(6):3016-24. doi:10.1021/pr901174z.

12. Adav SS, Cheow ES, Ravindran A, Dutta B, Sze SK. Label free quantitative proteomic analysis of secretome by Thermobifida fusca on different lignocellulosic biomass. J Proteomics. 2012;75(12):3694-706. doi:10.1016/j. jprot.2012.04.031.

13. Kataeva I, Foston MB, Yang S-J, Pattathil S, Biswal AK, Poole li FL, et al. Carbohydrate and lignin are simultaneously solubilized from unpretreated switchgrass by microbial action at high temperature. Energy Environ Sci. 2013;6(7):2186. doi:10.1039/c3ee40932e.

14. Ventorino V, Aliberti A, Faraco V, Robertiello A, Giacobbe S, Ercolini D, et al. Exploring the microbiota dynamics related to vegetable biomasses degradation and study of lignocellulose-degrading bacteria for industrial biotechnological application. Sci Rep. 2015;5:8161. doi:10.1038/srep08161.

15. Wilson D. Endophyte: the evolution of a term, and clarification of its use and definition. Oikos. 1995;73:274-6. doi:10.2307/3545919.

16. Purahong W, Hyde KD. Effects of fungal endophytes on grass and non-grass litter decomposition rates. Fungal Divers. 2010;47(1):1-7. doi:10.1007/s13225-010-0083-8.

17. Koide K, Osono T, Takeda H. Colonization and lignin decomposition of Camellia japonica leaf litter by endophytic fungi. Mycoscience. 2005;46(5):280-6. doi:10.1007/S10267-005-0247-7.

18. Xiong XQ, Liao HD, Ma JS, Liu XM, Zhang LY, Shi XW, et al. Isolation of a rice endophytic bacterium, Pantoea sp. Sd-1, with ligninolytic activity and characterization of its rice straw degradation ability. Lett Appl Microbiol. 2014;58(2):123-9. doi:10.1111/lam.12163.

19. Coutinho TA, Venter SN. Pantoea ananatis: an unconventional plant pathogen. Mol Plant Pathol. 2009;10(3):325-35 doi:10.1111/j.1364-3703.2009.00542.x.

20. Adams AS, Jordan MS, Adams SM, Suen G, Goodwin LA, Davenport KW, et al. Cellulose-degrading bacteria associated with the invasive woodwasp Sirex noctilio. ISME J. 2011;5(8):1323-31. doi:10.1038/ismej.2011.14.

21. De Maayer P, Chan WY, Rubagotti E, Venter SN, Toth IK, Birch PR, et al. Analysis of the Pantoea ananatis pan-genome reveals factors underlying its ability to colonize and interact with plant, insect and vertebrate hosts. BMC Genom. 2014;15:404. doi:10.1186/1471-2164-15-404.

22. Chandra R, Singh R. Decolourisation and detoxification of rayon grade pulp paper mill effluent by mixed bacterial culture isolated from pulp paper mill effluent polluted site. Biochem Eng J. 2012;61:49-58. doi:10.1016/j.bej.2011.12.004.

23. Dastager S, Deepa CK, Pandey A. Isolation and characterization of high-strength phenol-degrading novel bacterium of the Pantoea genus. Bioremediat J. 2009;13(4):171-9. doi:10.1080/10889860903341420.

24. Masai E, Kamimura N, Kasai D, Oguchi A, Ankai A, Fukui S, et al. Complete genome sequence of Sphingobium sp. strain SYK-6, a degrader of lignin-derived biaryls and monoaryls. J Bacteriol. 2012;194(2):534-5. doi:10.1128/JB.06254-11.

25. Deangelis KM, Sharma D, Varney R, Simmons B, Isern NG, Markilllie LM, et al. Evidence supporting dissimilatory and assimilatory lignin degradation in Enterobacter lignolyticus SCF1. Front Microbiol. 2013;4:280. doi:10.3389/fmicb.2013.00280

26. Liu D, Li J, Zhao S, Zhang R, Wang M, Miao Y, et al. Secretome diversity and quantitative analysis of cellulolytic Aspergillus fumigatus Z5 in the presence of different carbon sources. Biotechnol Biofuels. 2013;6(1):149. doi:10.1186/1754-6834-6-149.

27. Kumar R, Singh S, Singh OV. Bioconversion of lignocellulosic biomass: biochemical and molecular perspectives. J Ind Microbiol Biotechnol. 2008;35(5):377-91. doi:10.1007/s10295-008-0327-8.

28. Martinez D, Challacombe J, Morgenstern I, Hibbett D, Schmoll M, Kubicek CP, et al. Genome, transcriptome, and secretome analysis of wood decay fungus Postia placenta supports unique mechanisms of lignocellulose conversion. Proc Natl Acad Sci USA. 2009;106(6):1954-9. doi:10.1073/ pnas.0809575106. 
29. Bugg TD, Ahmad M, Hardiman EM, Singh R. The emerging role for bacteria in lignin degradation and bio-product formation. Curr Opin Biotechnol. 2011;22(3):394-400. doi:10.1016/j.copbio.2010.10.009.

30. Brown ME, Chang MC. Exploring bacterial lignin degradation. Curr Opin Chem Biol. 2014;19:1-7. doi:10.1016/j.cbpa.2013.11.015

31. Mathews SL, Pawlak J, Grunden AM. Bacterial biodegradation and bioconversion of industrial lignocellulosic streams. Appl Microbiol Biotechnol. 2015;99(7):2939-54. doi:10.1007/s00253-015-6471-y.

32. Levasseur A, Drula E, Lombard V, Coutinho PM, Henrissat B. Expansion of the enzymatic repertoire of the CAZy database to integrate auxiliary redox enzymes. Biotechnol Biofuels. 2013;6(1):41. doi:10.1186/1754-6834-6-41.

33. Horn SJ, Vaaje-Kolstad G, Westereng B, Eijsink VG. Novel enzymes for the degradation of cellulose. Biotechnol Biofuels. 2012;5(1):1-13. doi:10.1186/1754-6834-5-45

34. Boraston AB, Bolam DN, Gilbert HJ, Davies GJ. Carbohydrate-binding modules: fine-tuning polysaccharide recognition. Biochem J. 2004;382:769-81. doi:10.1042/BJ20040892.

35. Stevenson DM, Weimer PJ. Expression of 17 genes in Clostridium thermocellum ATCC 27405 during fermentation of cellulose or cellobiose in continuous culture. Appl Environ Microbiol. 2005;71(8):4672-8. doi:10.1128/AEM.71.8.4672-4678.2005.

36. Himmel ME, Xu Q, Luo Y, Ding S-Y, Lamed R, Bayer EA. Microbial enzyme systems for biomass conversion: emerging paradigms. Biofuels. 2010;1 (2):323-41. doi:10.4155/bfs.09.25.

37. Lochner A, Giannone RJ, Rodriguez M Jr, Shah MB, Mielenz JR, Keller M, et al. Use of label-free quantitative proteomics to distinguish the secreted cellulolytic systems of Caldicellulosiruptor bescii and Caldicellulosiruptor obsidiansis. Appl Environ Microbiol. 2011;77(12):4042-54. doi:10.1128/ AEM.02811-10.

38. Sun J, Tian C, Diamond S, Glass NL. Deciphering transcriptional regulatory mechanisms associated with hemicellulose degradation in Neurospora crassa. Eukaryot Cell. 2012;11(4):482-93. doi:10.1128/EC.05327-11.

39. Zhao Z, Liu H, Wang C, Xu JR. Comparative analysis of fungal genomes reveals different plant cell wall degrading capacity in fungi. BMC Genom. 2013;14:274. doi:10.1186/1471-2164-14-274.

40. Navarrete M, Callegari E, Eyzaguirre J. The effect of acetylated xylan and sugar beet pulp on the expression and secretion of enzymes by Penicillium purpurogenum. Appl Microbiol Biotechnol. 2012;93(2):723-41. doi:10.1007/s00253-011-3744-y.

41. Reinhold-Hurek B, Hurek T. Living inside plants: bacterial endophytes. Curr Opin Plant Biol. 2011;14(4):435-43. doi:10.1016/j.pbi.2011.04.004.

42. Tiwari R, Singh S, Nain PK, Rana S, Sharma A, Pranaw K, et al. Harnessing the hydrolytic potential of phytopathogenic fungus Phoma exigua ITCC 2049 for saccharification of lignocellulosic biomass. Bioresour Technol. 2013;150:228-34. doi:10.1016/j.biortech.2013.10.007.

43. Tiwari R, Singh S, Singh N, Adak A, Rana S, Sharma A, et al. Unwrapping the hydrolytic system of the phytopathogenic fungus Phoma exigua by secretome analysis. Process Biochem. 2014;49(10):1630-6. doi:10.1016/j. procbio.2014.06.023.

44. Masai E, Katayama Y, Kubota S, Kawai S, Yamasaki M, Morohoshi N. A bacterial enzyme degrading the model lignin compound $\beta$-etherase is a member of the glutathione-S-transferase superfamily. FEBS Lett. 1993;323(1):135-40. doi:10.1016/0014-5793(93)81465-C.

45. Masai E, Kubota S, Katayama Y, Kawai S, Yamasaki M, Morohoshi N. Characterization of the $\mathrm{C}$ alpha-dehydrogenase gene involved in the cleavage of beta-aryl ether by Pseudomonas paucimobilis. Biosci Biotechnol Biochem. 1993;57(10):1655-9. doi:10.1271/bbb.57.1655.

46. Colpa DI, Fraaije MW, van Bloois E. DyP-type peroxidases: a promising and versatile class of enzymes. J Ind Microbiol Biotechnol. 2014;41(1):1-7. doi:10.1007/s10295-013-1371-6.
47. Majumdar S, Lukk T, Solbiati JO, Bauer S, Nair SK, Cronan JE, et al. Roles of small laccases from Streptomyces in lignin degradation. Biochemistry. 2014;53(24):4047-58. doi:10.1021/bi500285t.

48. Ihssen J, Reiss R, Luchsinger R, Thony-Meyer L, Richter M. Biochemical properties and yields of diverse bacterial laccase-like multicopper oxidases expressed in Escherichia coli. Sci Rep. 2015;5:10465. doi:10.1038/ srep10465.

49. Potumarthi R, Baadhe RR, Nayak P, Jetty A. Simultaneous pretreatment and saccharification of rice husk by Phanerochete chrysosporium for improved production of reducing sugars. Bioresour Technol. 2013;128:113-7. doi:10.1016/j.biortech.2012.10.030.

50. Jing D. Improving the simultaneous production of laccase and lignin peroxidase from Streptomyces lavendulae by medium optimization. Bioresour Technol. 2010;101(19):7592-7. doi:10.1016/j.biortech.2010.04.087.

51. Shi X, Liu Q, Ma J, Liao H, Xiong X, Zhang K, et al. An acid-stable bacterial laccase identified from the endophyte Pantoea ananatis Sd-1 genome exhibiting lignin degradation and dye decolorization abilities. Biotechnol Lett. 2015;37(11):2279-88. doi:10.1007/s10529-015-1914-1.

52. Zamocky M, Hallberg M, Ludwig R, Divne C, Haltrich D. Ancestral gene fusion in cellobiose dehydrogenases reflects a specific evolution of GMC oxidoreductases in fungi. Gene. 2004;338(1):1-14. doi:10.1016/j. gene.2004.04.025.

53. Prongjit M, Sucharitakul J, Palfey BA, Chaiyen P. Oxidation mode of pyranose 2-oxidase is controlled by $\mathrm{pH}$. Biochemistry. 2013;52(8):1437-45. doi:10.1021/bi301442x.

54. Baldrian P, Valaskova V. Degradation of cellulose by basidiomycetous fungi. FEMS Microbiol Rev. 2008;32(3):501-21. doi:10.1111/j.1574-6976.2008.00106.x.

55. Ghose TK. Measurement of cellulase activities. Pure Appl Chem. 1987;59(2):257-68. doi:10.1351/pac198759020257.

56. Bailey MJ, Biely P, Poutanen K. Interlaboratory testing of methods for assay of xylanase activity. J Biotechnol. 1992;23(3):257-70. doi:10.1016/0168-1656(92)90074-J.

57. Miller GL. Use of dinitrosalicylic acid reagent for determination of reducing sugar. Anal Chem. 1959:31(3):426-8. doi:10.1021/ac60147a030.

58. Perry JD, Morris KA, James AL, Oliver M, Gould FK. Evaluation of novel chromogenic substrates for the detection of bacterial beta-glucosidase. J Appl Microbiol. 2007;102(2):410-5. doi:10.1111/j.1365-2672.2006.03096.x.

59. Shi Y, Chai L, Tang C, Yang Z, Zhang H, Chen R, et al. Characterization and genomic analysis of kraft lignin biodegradation by the beta-proteobacterium Cupriavidus basilensis B-8. Biotechnol Biofuels. 2013;6(1):1. doi:10.1186/1754-6834-6-1.

60. Nakagawa Y, Sakamoto Y, Kikuchi S, Sato T, Yano A. A chimeric laccase with hybrid properties of the parental Lentinula edodes laccases. Microbiol Res. 2010;165(5):392-401. doi:10.1016/j.micres.2009.08.006.

61. Yin Y, Mao X, Yang J, Chen X, Mao F, Xu Y. dbCAN: a web resource for automated carbohydrate-active enzyme annotation. Nucleic Acids Res. 2012;40(Web Server issue):W445-51. doi:10.1093/nar/gks479.

62. Lombard V, Golaconda Ramulu H, Drula E, Coutinho PM, Henrissat B. The carbohydrate-active enzymes database (CAZy) in 2013. Nucleic Acids Res. 2014:42(Database issue):D490-5. doi:10.1093/nar/gkt1178.

63. Petersen TN, Brunak S, von Heijne G, Nielsen H. SignalP 4.0: discriminating signal peptides from transmembrane regions. Nat Methods. 2011;8(10):785-6. doi:10.1038/nmeth.1701.

64. Livak KJ, Schmittgen TD. Analysis of relative gene expression data using real-time quantitative PCR and the $2^{-\triangle \triangle C T}$ method. Methods. 2001;25(4):402-8. doi:10.1006/meth.2001.1262.

65. Shevchenko A, Tomas H, Havlis J, Olsen JV, Mann M. In-gel digestion for mass spectrometric characterization of proteins and proteomes. Nat Protoc. 2006;1(6):2856-60. doi:10.1038/nprot.2006.468. 